DOI: http://dx.doi.org/10.18764/2358-4319.v10n4p76-99

\title{
Belas, sim! Recatadas e do lar, não! Violências, feminilidades outras e resistências de professoras da educação básica
}

\author{
Ivan Amaro' \\ Luciana Izis Silva de Abreu²
}

\section{RESUMO}

Este artigo objetiva apresentar dados de pesquisa concluída com a intenção de levantar/problematizar questões sobre configurações de feminilidades que cercam as professoras da educação básica, as violências a que estão sujeitas e as estratégias utilizadas para resistir e, portanto, avançar em prol de uma visão emancipatória de docência. A partir das trajetórias de vida, acessamos informações de cinco professoras que não se encaixam em normalizações de gênero padrão: uma heterossexual, que vive livremente sua sexualidade, seus prazeres; uma transexual; uma lésbica, uma negra e lésbica e um professor que performatiza uma drag queen. As questões disparadoras foram: como estas docentes performatizam uma visão de feminilidade? Que violências emergem dessas performances? Que mecanismos de resistência lançam mão contra estas violências? Utilizamos o conceito de "conhecimento venenoso" como ferramenta de análise. Dentre os diversos achados, ressaltamos a possibilidade de pensar em outras configurações da categoria "mulher" para resistir aos preconceitos, às discriminações, às violências de gênero. Há indícios de que outras feminilidades habitam o espaço da docência, indicando uma resistência à homogeneização/universalização do conceito de feminilidade, apontando para uma concepção plural, qual seja, feminilidades outras na docência.

Palavras-chave: Feminilidades docentes. Violência. Sofrimento. Resistência.

1 Doutor em Educação (UNICAMP). Professor do Programa de Pós-Graduação em Educação, Cultura e Comunicação em Periferias (UERJ) Urbanas. Coordenador do NuDES (Núcleo de Estudos e Pesquisas em Diferenças, Educação, Gênero e Sexualidades - CNPq/UERJ) - E-mail: ivanamaro.uerj@gmail.com

2 Mestra em Educação, Cultura e Comunicação em Periferias Urbanas (UERJ). Professora da Educação Básica do Município de Duque de Caxias - RJ. E-mail: lu.izis.abreu@gmail.com 


\section{Pretty, yes! Modest and housewife, not! Violences, feminities other and resistance of teachers of basic education}

\section{ABSTRACT}

This article aims to present data of a completed research with the intention of raising / problematizing questions about the configurations of femininities that surround the basic education teachers, the violence they are subjected to and the strategies used to resist and, therefore, to advance towards an emancipatory vision of teaching. From the life trajectories, we access information from five teachers who do not fit into standard gender normalizations: a heterosexual who lives freely her sexuality, her pleasures; a transsexual; a lesbian, a black lesbian, and a teacher who performs a drag queen. The triggering questions were: how do these teachers performatize a vision of femininity? What violence emerges from these performances? What mechanisms of resistance do they resort to? We use the concept of "poison knowledge" as a tool for analysis. Among the several findings, we highlight the possibility of thinking of other configurations of the category "woman" to resist prejudice, discrimination, and gender violence. There are indications that other femininities inhabit the teaching space, indicating a resistance to the homogenization / universalization of the concept of femininity, pointing to a plural conception, that is, other femininities in teaching.

Keywords: Teaching femininity, Violence, Suffering, Resistance

\section{¡Bellas, sí! ¡Recatadas y del hogar, no! Violencias, feminilidades otras y resistencias de profesoras de educación básica}

\section{RESUMEN}

Este artículo objetiva presentar datos de una investigación concluida con la intención de plantear/problematizar cuestiones sobre configuraciones de feminilidades que rodean a las profesoras de educación básica, las violencias las que están sometidas y las estrategias de resistencia y, por lo tanto, avanzar en pro de una visión emancipatoria de docencia. A partir de las trayectorias de vida, accedemos a informaciones de cinco profesoras que no se incluyen en normalizaciones de género estándar: una heterosexual que vive libremente su sexualidad, sus placeres; una transexual; una lesbiana, una negra y lesbiana y un profesor que actúa 
como drag queen. Las cuestiones alarmantes fueron: ¿cómo estas docentes demuestran una visión de feminilidad? ¿Qué violencias surgen de esas performances? ¿Qué mecanismos de resistencia se utilizan contra estas violencias? Utilizamos el concepto de "conocimiento venenoso" como herramienta de análisis. Entre los diversos hallazgos, resaltamos la posibilidad de pensar en otras configuraciones de la categoría "mujer" para resistir a los prejuicios, a las discriminaciones, a las violencias de género. Hay señales de que otras feminilidades habitan el espacio de la docencia, indicando una resistencia a la homogeneización/ universalización del concepto de feminilidad, señalando para una concepción plural, sea o no sea, feminilidades otras en la docencia.

Palabras clave: Feminilidades docentes, Violencia, Sufrimiento, Resistencia.

\title{
Quais vidas importam? pontos de partida de nossa investigação
}

\begin{abstract}
Afirmar que uma vida pode ser lesada, por exemplo, ou que pode ser perdida, destruída ou sistematicamente negligenciada até a morte é sublinhar não somente a finitude de uma vida (o fato de que a morte é certa), mas também sua precariedade (porque a vida requer que várias condições sociais e econômicas sejam atendidas para ser mantida como uma vida). A precariedade implica viver socialmente, isto é, o fato de que a vida de alguém está sempre nas mãos do outro. Isso implica estarmos expostos não somente àqueles que conhecemos, mas também àqueles que não conhecemos, isto é, dependemos das pessoas que conhecemos, das que conhecemos superficialmente e das que desconhecemos totalmente. (BUTLER, 2015, p. 31)
\end{abstract}

No momento em que elaboramos este artigo, o país passa por um quadro sombrio de retrocessos de nossos direitos e de fortes ataques à democracia. Por meio de um golpe jurídico-político-midiático gestado desde as eleições de 2014 e que se consumou, em 2016, com o afastamento da Presidenta Dilma Roussef, o país parece ter entrado num verdadeiro estado de exceção, paradigma de governo que tem se tornado dominante no jogo político contemporâneo e que se apresenta como um espaço de indeterminação entre democracia e absolutismo (AGAMBEN, 2004). 
Nesse sentido, os diversos movimentos nos campos do executivo, do legislativo e judiciário corroboram para um alarmante desmanche de direitos sociais e de ataques e violências diversas desferidas contra categorias inteiras de cidadãos - funcionários/as públicos/as, quilombolas, indígenas, negros/as, mulheres, gays, transexuais, trabalhadores/as.

No Brasil, o quadro de violência é marcadamente definido pelos cruzamentos entre gênero, raça e classe. Como afirma Butler (2015), nossas vidas se interconectam, são interdependentes e nos levam a questionar: que vidas importam? Tais ataques, interdições, censura e regulação ao caráter democrático da sociedade brasileira atingem, também, o espaço da escola, seus sujeitos, suas práticas, seus currículos, suas finalidades. Esta situação impõe a nós, educadores/as, pesquisadores/as assumirmos a resistência e a defesa da produção de conhecimentos que se contraponham aos discursos do senso comum ou enviesados política e teoricamente.

A violência é algo abominável para todas as pessoas, e em qualquer sociedade. Porém, parece naturalizado que a violência que alguns grupos sociais sofrem é aceitável. Os discursos constituídos colocam como normal, por exemplo, um homem violentar uma mulher porque ela estava "se oferecendo ao usar roupas sensuais". Há uma lógica do "estupro corretivo" como forma de "ensinar" lésbicas a serem "mulheres". Há uma outra lógica naturalizada de que gays, transexuais e travestis devem apanhar na rua para aprenderem a "ser homens". Nesse sentido, a violência é aclamada quando serve para reiterar normas inteligíveis ou reafirmar a supremacia masculina sexista e heterossexual.

Podemos perceber que há uma norma presente que define as vidas que merecem solidariedade humana e as que não merecem tal tratamento. Uma vida só pode ser considerada como tal quando corresponde aos padrões produzidos socialmente: não há como existir uma vida se ela não se submeter aos enquadramentos. A inteligibilidade ${ }^{3}$ se faz presente e toda'vida' que transcende esta norma se torna mais vulnerável à violência. Vidas que estão para além do padrão cisgênero ${ }^{4}$, hete-

3 Trata-se de um conceito em que os gêneros são coerentes quando estão de acordo com a norma do sexo: alguém que nasce com pênis será homem, deve performatizar signos ditos masculinos. Alguém que nasce com vagina será mulher e deve performatizar os signos considerados femininos. A inteligibilidade é um conceito que trabalha os gêneros como binários em que estão calcados numa matriz heteronormativa.

40 terno cigênero se refere às pessoas cujo gênero é o mesmo que o designado em seu nascimento. 
rossexual, quando são perdidas, muitas vezes, não são lamentadas, pois não possuíam o status de vida. Um corpo sempre está entregue à vulnerabilidade do outro. Um corpo está sempre exposto a enquadramentos que determinam vidas que podemos ou não chorar. Butler (2015, p. 17) denomina como precarização da vida: “O 'ser' da vida é ele mesmo constituído por meios seletivos; como resultado, não podemos fazer referência a esse "ser" fora das operações de poder e devemos tornar mais precisos os mecanismos específicos de poder mediante os quais a vida é produzida. (BUTLER, 2015, p.17)

Este artigo apresenta alguns achados de estudo finalizado, com o título "Nem recatadas, nem do lar: a performatividade de professoras, violências e outras feminilidades", vinculado ao NuDES (Núcleo de Estudos e Pesquisas em Diferenças, Gênero, Educação e Sexualidades) da UERJ (Universidade do Estado do Rio de Janeiro) e certificado pelo CNPq (Conselho Nacional de Desenvolvimento Científico e Tecnológico) e que compõe uma pesquisa mais ampla, intitulada "Educação, diferença, gênero e sexualidades: potencialidades de um currículo queer e decolonial nos cotidianos escolares de periferias urbanas"

Para efeito desse artigo, nos debruçamos sobre a categoria "gênero" como conceito analítico com intenção de levantar algumas questões para pensarmos as configurações de feminilidades que cercam as professoras da educação básica, as violências a que estão sujeitas e que estratégias utilizam para resistir e, portanto, avançar em prol de uma visão emancipatória de docência.

Assim, as vidas que importam para nós não se encaixam em normas e normalizações que são consideradas padrão e consolidadas histórica e culturalmente. As vidas que importam são aquelas que se produzem e são produzidas em processos de desconstrução. São mulheres docentes transexuais, lésbicas, negras, drag queens, bem resolvidas, que vivem plenamente sua sexualidade, seus desejos e seus prazeres. Enfim, consideramos mulheres que performatizam outras feminilidades que não se encaixam numa visão de feminino universal. Estas mulheres docentes também estão nas escolas e realizam um trabalho pedagógico em um espaço que não parece ser delas. Um espaço que parece violentá-las cotidianamente, não só pelo simples fato de serem mulheres, mas

5 Programa Prociência - UERJ, financiado pela FAPERJ ( Fundação de Amparo à Pesquisa do Estado do Rio de Janeiro), coordenada pelo Prof. Dr. Ivan Amaro. 
por serem mulheres que não se inscrevem numa simbologia branca, burguesa e heteronormativa.

A depender da exposição que vivenciam, é possível que sejam violentadas a performatizarem uma imagem que deve condizer com o que se espera como padrão de uma professora. As mulheres participantes da pesquisa trazem sentidos de feminilidades diversos, que foram construídos ao longo de suas trajetórias de vida. Por isso, a definição de uma metodologia que respeitasse estas trajetórias foi crucial para pensarmos formas alternativas de produzir conhecimento. Nesse sentido, os estudos feministas, conforme argumenta Coutinho (2006), permitiram uma abertura para outras metodologias diversas, para dar conta de acessar o universo não só da produção da linguagem, mas também das condições concretas que a linguagem também produz.

Isso acontece devido à insatisfação com outros métodos já tradicionais que não davam conta de contemplar as perspectivas que os estudos sobre mulheres traziam. Nesta investigação, consideramos de fundamental importância as narrativas produzidas pelas colaboradoras. De acordo com Coutinho (2006), elas têm se constituído como procedimento básico nas investigações sobre gênero, pois têm o poder de captar vivências, experiências, ações, sentimentos resgatados a partir da memória para a compreensão do passado e do presente. Esta escolha também nos permite pensar que é possível captar as resistências que se colocam nas formas e estratégias de sobrevivência dessas professoras no contexto de violências. Silva (2002) considera que as histórias de vida colaboram para dar visibilidade para os espaços de resistência, o que é bastante potente para pensarmos formas de enfrentamento da violência sofrida por professoras. As professoras participantes desta pesquisa são atuantes em escolas públicas no estado do Rio de Janeiro ${ }^{6}$. Trabalhamos com um total de 04 professoras e 01 professor $^{7}$ dos municípios do Rio de Janeiro, Belford Roxo, Duque de Caxias e Niterói.

A professora Carla se declara uma mulher que vive livremente sua sexualidade. Autodefine-se como uma "mulher de vida alegre". Já sofreu assédio por parte de um ex-diretor da escola em que trabalhava,

6 Os nomes das participantes são fictícios para garantir a privacidade.

7 Apesar de termos 01 professor participando da pesquisa, optamos por utilizar de forma genérica a referência a "professoras", pois, além de serem maioria no magistério, o professor participante se inscreve numa possibilidade de vivência de feminilidade não considerada hegemônica. 
considera-se recriminada, no ambiente de trabalho, por seu comportamento e sua forma de se vestir: "Me visto de forma bem provocante mesmo, mesmo na escola".

A professora Letícia trabalha em Belford Roxo há 04 anos, mas já atua há 08 anos como docente da Educação Infantil, no município do Rio de Janeiro. É uma mulher negra e lésbica. Em diversos momentos de nossas conversas, colocou a situação de ter de se "esconder" na escola por conta de sua orientação sexual. Considera que o preconceito por ser negra já é o bastante para "ter de aguentar as violências que vivenciam no ambiente de trabalho". No entanto, ela se considera "barraqueira", pois não admite assédios de quaisquer ordens por parte da direção da escola. Tal comportamento é visto como agressivo e não condizente com o que se espera de uma professora: ponderação, voz baixa, submissão.

A professora Jasmine, docente no município do Rio de Janeiro e diretora de uma escola do Estado atua na docência há 10 anos. A escolha dela para participar da pesquisa se deu por ser uma mulher transexual e negra. Ela nos informou que realizou seu processo transexualizador após 5 anos de atuação e, por isso, sofreu diversas violências por não se encaixar num padrão de feminilidade docente. Em nossa conversa, problematizou as diversas formas que o preconceito e a discriminação, como manifestação de violência, são produzidos, principalmente, por outras colegas da escola, além da violência já característica dos professores homens. Em suas falas, nos surpreende ao afirmar que sofreu pouco com o prenconceito de alunos/as, bem como de seus/suas pais/mães.

A professora Cristiane atua na rede estadual do Rio de Janeiro há 12 anos. Sua escolha se deu por ser uma mulher que assume sua orientação sexual lésbica, por ser casada e por trabalhar no mesmo local que a esposa.

A escolha do professor João, que trabalha na rede municipal de Duque de Caxias, é pastor de uma igreja evangélica, atua como dirigente sindical e, nas horas vagas, performatiza Laura, uma Drag Queen. Ele/a relata diversas violências vividas nas correlações de performance da Drag Queen e da docência. Sua participação contribui para ampliar nosso escopo acerca do conceito de feminilidade, alargando-o para vivências de gênero não-binárias e para a pluralidade: feminilidades.

Nas questões levantadas, priorizamos as seguintes: como as performances vivenciadas por estas docentes são vistas no ambiente educacional? Em que situações, as violências emergem? Que tipos de 
assédios sofrem no espaço da escola por não se encaixarem num enquadre padrão de docência? Que características se revestem as violências sofridas? Que resistências se colocam para o enfrentamento dessas violências?

Assim, tais questões nos encaminharam para trabalharmos sob a perspectiva de gênero que têm balizado nossas pesquisas e situado a identidade docente, a partir da categoria "mulher", que foge às lógicas padrões de feminilidades, indicando nossos objetivos, percursos metodológicos e referenciais teóricos que nos orientam. Na sequência, apresentamos um contexto mais geral da violência que temos vivenciado e tentado enfrentar no campo das relações de gênero. Focalizaremos, em seguida, as diversas manifestações de violência sofridas pelas participantes da pesquisa em articulação com a feminilidade que se performatiza no espaço escolar. Na seção seguinte, apresentamos os achados da pesquisa, relacionando-os a uma análise das violências vivenciadas no cotidiano do trabalho das participantes. Por fim, apontamos como as estratégias de resistência têm sido empreendidas, num caráter emancipatório, para viverem suas feminilidades livremente no exercício da docência.

\section{Gênero e a construção de outras feminilidades na docência}

Ao direcionarmos nossos olhares sobre as diversas feminilidades que configuram o "ser professora" nos orientamos a partir de uma perspectiva do conceito de gênero e, consequentemente, de feminilidade, que não é estável, nem envolto em certezas. Para Harding (1993), no início das pesquisas que tomaram o foco das experiências femininas, houve uma correlação muito estreita com teorias tradicionais que obscureciam outras formas de conhecimento e de reconhecimento das diferenças que envolvem os estudos feministas. Questiona que tais estudos tenham desviado seu foco para o debate com pesquisadoras não-feministas, o que levou a uma atenção ao diálogo não com mulheres, mas com patriarcas. Dessa forma, ela coloca em dúvida a concepção do caráter "mítico do 'homem' universal e essencial que foi sujeito e objeto paradigmáticos das teorias não-feministas" (HARDING, 1993, p. 8).

Do mesmo modo, a análise que toma como sujeito e objeto a ideia de uma mulher universal situa estudos de gênero a partir da "experiência social de mulheres brancas, ocidentais, burguesas e heterossexuais". Tal situação, segundo Harding (1993), 
acaba por nos parecer particularmente suspeito, assim que começamos a analisar a experiência de qualquer outro tipo de mulher. As teorias patriarcais que procuramos estender e reinterpretar não foram criadas para explicar a experiência dos homens em geral, mas tão-somente a experiência de homens heterossexuais, brancos, burgueses e ocidentais. (HARDING, 1993, p. 9)

Ao realizarmos esta pesquisa com professoras que se afastam da perspectiva histórica de mulher cuidadora, afável, sensível, "recatada" e "do lar", para nos aproximarmos de professoras que são mulheres que vivem sua sexualidade livremente, que são transexuais, que são lésbicas, que são feministas, nos situamos na noção de que gênero não é uma categoria que serve apenas para posicionar homens e mulheres em oposições. É, antes, um conceito que nos ajuda a compreender os sistemas simbólicos, articulados em redes de significado e redes de poder que compõem o espaço social como um todo, em suas dimensões econômicas, políticas, culturais. (SCOTT, 1995; NICHOLSON, 2000). Nesse sentido, concordamos com a premissa de que os estudos feministas têm fundamental relevância na evidência de que "não há e nunca houve'homens' genéricos - existem apenas homens e mulheres classificados em gêneros." (HARDING, 1993, p. 09). Do mesmo modo, desaparece também a ideia de uma mulher essencial, universal. Afirma, portanto, que "temos uma infinidade de mulheres que vivem em intrincados complexos históricos de classe, raça e cultura." (HARDING, 1993, p. 09).

Connell (2015) também tensiona esta visão de uma masculinidade ou feminilidade universal. Ela apresenta as diversas visões conflitantes sobre as diferenças de gênero que perpassam significados inscritos nas diferenças reprodutivas, biológicas, psíquicas, intelectuais. A autora coloca em tensão as visões que denomina como "corpo como máquina", que é concebida pelas explicações biológicas; a ideia do corpo como tela, em que a cultura é que define os modos de ser homem ou mulher.

O fato de haver uma diferença reprodutiva entre machos e fêmeas humanos praticamente não é controverso, mas seu significado com certeza o é. Sobre esta questão, abordagens em relação ao gênero divergem claramente. Algumas tratam o corpo como uma espécie de máquina que manufatura diferenças de gênero, outras tratam o corpo como um tipo de tela em que a cultura pinta imagens de gênero e há aquelas 
que tentam grampear as imagens da tela na máquina. Nenhuma dessas abordagens é uma maneira satisfatória de compreender o problema. (CONNELL, 2015, p. 90-91)

Ao refletir sobre diversas investigações ${ }^{8}$ que discutem a "similaridade sexual", a autora procura derrubar dicotomias e mesmo a ideia de que homens e mulheres são diferentes: mulheres são passivas, cuidadosas, influenciáveis, emotivas, intuitivas, sexualmente abnegadas e fiéis; os homens são agressivos, inflexíveis, racionais, analíticos, infiéis sexualmente. Ela atribui que "na psicologia pop, as diferenças corporais e os efeitos sociais são ligados pela ideia de uma dicotomia de caráter" (CONNELL, 2015, p. 101). Aponta, ainda, que várias investigações indicam que, na verdade, há "similaridades sexuais"." A partir do estudo de Maccoby e Jacklin (1975 apud CONNELL, 2015), considera que

não é verdade que meninas são mais sociáveis do que meninos, que são mais influenciáveis do que eles, que têm a autoestima mais baixa, que são melhores no aprendizado básico, enquanto eles são melhores em processos cognitivos de alto nível, que eles são mais analíticos, que elas são mais afetadas por herança genética e eles, por estímulos do ambiente, que elas não têm motivação para o sucesso ou não são ouvintes, enquanto eles são visuais. No fim das contas, todas essas crenças são mitos. (CONNELL, 2015, p. 103)

Por fim, considera que as pesquisas acerca da ideia de similaridade de gênero acabaram por refutar o conceito de dicotomia de caráter. Para ela, os corpos são construídos socialmente em que o gênero ganha uma feição específica denominada de "corporificação social".

Nossos corpos são interconectados por meio de práticas sociais e de coisas que fazemos em nosso cotidiano. Simultaneamente, corpos são objetos e agentes de práticas sociais. Os mesmos corpos, ao mesmo

8 Cita a pesquisa de Rosalind Rosenberg (1982) - Beyond separate spheres (Para além de esferas separadas) em que já aponta uma visão contrária ao pensamento dominante no século $\mathrm{XIX}$ que indicava que havia diferenças mentais diferentes entre homens e mulheres. Ela constatou que esta era uma visão infundada. Não havia diferenças significativas intelectuais conforme o gênero.

9 Connell (2015) cita a pesquisa de Maccoby e Jaclin (1975) em que, mesmo investigando outras variáveis, chegam a mesma conclusão que Rosenberg (1982): não há diferenças significativas entre homens e mulheres. 
tempo, são ambos. As práticas em que corpos são envolvidos formam estruturas sociais e trajetórias pessoais, o que, por sua vez, fornece condições para novas práticas nas quais os corpos são envolvidos. (CONNELL, 2015, p. 111-112)

Pensando a partir dessa instabilidade e que as práticas sociais são elas, também, frutos da linguagem e mesmo materializações de vivências, não é possível imaginarmos uma ideia fixa do que seja masculinidade ou feminilidade. Para Fausto-Sterling (2001), as relações entre sexo e gênero também se constituem em processos constituídos com as articulações dos aspectos sociais.

O sexo de um corpo é simplesmente complexo demais. Não existe o isso ou aquilo. Antes, existem nuances de diferença, [...] rotular alguém homem ou mulher é uma decisão social. Podemos utilizar o conhecimento científico para nos ajudar a tomar a decisão, mas só nossas crenças sobre o gênero - e não a ciência - podem definir nosso sexo. Além disso, nossas crenças sobre o gênero também afetam o tipo de conhecimento que os cientistas produzem sobre o sexo. (FAUSTO-STERLING, 2001, p. 15)

Diante disso, partimos da seguinte indagação: o que comporta, como características, as identidades de professoras que não se encaixam na concepção de um suposto feminino hegemônico, que tem sido naturalizado pelos discursos e pelas performances vigentes? Que violências se impõem em nome de uma feminilidade padrão?

Apesar de a pesquisa apresentar um espectro mais amplo que parte das trajetórias de vida em que as participantes narraram suas experiências escolares e a caminhada ao magistério, nos deteremos nas vivências de violências contadas no exercício da docência e que, dessa forma, constituem suas feminilidades. Na seção seguinte, trataremos de alguns referenciais sobre violência e apresentaremos alguns dados da pesquisa.

O cenário da violência no Brasil: intersecções entre gênero, classe e raça

Conforme temos apresentado, ao compreendermos que a categoria mulher não se inscreve numa perspectiva de completude e 
estabilidade, tensionamos também os sentidos de "ser professora" que se posicionam em outras feminilidades e, portanto, configuram outras docências. Nesse sentido, a docência ancorada historicamente na figura maternal, afável, carinhosa, sensível como características "naturais" da mulher, sofre mudanças e abalos no campo educacional.

A escola, como espaço privilegiado do trabalho docente, é onde as diversas violências se manifestam. Em 2013, a OCDE (Organização para Cooperação e Desenvolvimento Econômico) apresentou relatório do "Teaching and Learning International Survey" (TALIS) ${ }^{10}$, indicando que, "no Brasil, mais de um terço dos professores (34\%) estão em escolas cujos diretores afirmam que verificam intimidação ou ofensa verbal entre os alunos semanalmente. Esse é o maior percentual verificado entre os países participantes da pesquisa." (BRASIL/INEP, 2014, p. 16). Isso implica pensarmos que as relações entre escola e violência são complexas e constituem amplo leque para pesquisas e estudos acerca das várias violências que ali se manifestam. Ristum (2010) aponta que a violência escolar não se localiza apenas em um viés. Para ela, há a violência na, da e contra a escola.

Os signos femininos são performatizados e ao falarmos sobre eles, estamos falando também de uma violência que os permeia. Podemos citar que, desde mulheres que performatizam o gênero de maneira hegemônica, ou mesmo os gays que são vistos como afeminados, são ainda mais hostilizados, pois, além da homofobia, o gênero destes é lido como feminino. Corpos femininos estão numa vulnerabilidade em que a violência pode acontecer a qualquer momento. Mulheres se tornam testemunhas de violência que muitas vezes nem mesmo vivenciaram, mas estas estão em suas subjetividades, pois ser chamada de mulher já envolve estas violências.

Waiselfisz (2015) aponta no Mapa da Violência 2015 que o número de assassinatos de mulheres entre 1980 e 2013 aumentou em

10 A Pesquisa Internacional sobre Ensino e Aprendizagem (TALIS - Teaching and Learning International Survey) investigou o ambiente de ensino e aprendizagem em escolas de educação básica de 34 países durante os anos de 2012 e 2013. A TALIS foi coordenada em âmbito internacional pela Organização para Cooperação e Desenvolvimento Econômico (OCDE). No Brasil, a pesquisa foi organizada pelo Instituto Nacional de Estudos e Pesquisas Educacionais Anísio Teixeira (Inep). O relatório internacional (OECD, 2014a), elaborado pela OCDE, trata dos resultados da pesquisa considerando todos os países participantes e pode ser acessado no site da referida organização http://www.oecd.org/edu/ ou no relatório produzido pelo INEP, no endereço:http://download.inep.gov.br/acoes_internacionais/ pesquisa_talis/2013/talis2013_relatorio_brasil.pdf 
$252 \%$, no Brasil, colocando o país na $5^{\text {a }}$ colocação no ranking mundial. De acordo com dados consolidados da Organização Mundial da Saúde (OMS), apenas El Salvador, Colômbia, Guatemala e a Federação Russa apresentam taxas superiores as do Brasil. Se tomarmos apenas a América do Sul, ocupamos o $1^{\circ}$ lugar em mortes de mulheres.

Em 1980, a taxa era de 2,3 vítimas por 100 mil habitantes. Em 2013 , passou para 4,8 , um aumento de $111,1 \%$. No período compreendido entre 2003 e 2013, o número de mulheres vitimadas passou de 3.937 para 4.762, um aumento de $21 \%$ na década. Isso representa um número de 13 mortes por dia. Se tomarmos o crescimento da população feminina, que nesse período passou de 89,8 para 99,8 milhões (crescimento de $11,1 \%)$, vemos que a taxa nacional de homicídio, que em 2003 era de 4,4 por 100 mil mulheres, passa para 4,8 em 2013 , crescimento de $8,8 \%$ na década.

Na relação raça/cor, há um aumento drástico de vitimização da população negra, enquanto há uma queda significativa de mulheres brancas. O número de 1.747 vítimas, em 2003, cai para 1.576, em 2013. Estes números representam uma queda de $9,8 \%$, na década. Por outro lado, o número de mortes de mulheres negras aumenta $54,2 \%$ no mesmo período, passando de 1.864 para 2.875 vítimas. Mesmo com a vigência da Lei no 11.340/2006 (Lei Maria da Penha), este movimento permanece. $O$ número de vítimas cai $2,1 \%$ entre as mulheres brancas e aumenta em $35,0 \%$ entre as negras.

Apesar de algumas conquistas e avanços da luta feminista e das mulheres, em pleno século XXI, ainda lidamos com este cenário de grande violência, o que contrasta significativamente com os ideais dos movimentos democráticos dos anos 1980, bem como com todas as lutas empreendidas e contínuas dos movimentos sociais por melhores condições de vida da população brasileira. Além disso, estes dados apontam a necessidade clara de empreendermos maiores processos formativos e educativos em prol da luta contra preconceitos, discriminações e violências que envolvem as relações de gênero na sociedade e no campo da educação também.

A escola, como espaço da ação docente, é uma instituição complexa e que atravessa diversas situações de violência. Para Ristum (2010), se evidenciam três formas de violência no espaço escolar: a violência contra, na e da escola. A "violência contra a escola" se materializa a partir das condições inadequadas de trabalho para seus/suas docentes, das 
condições estruturais desfavoráveis e a agressão de grupos ou pessoas externas à escola. Fazem parte dessa violência o conjunto de políticas e práticas que têm constituído um processo histórico de desqualificação, de precarização e de proletarização dos profissionais docentes. De acordo com a autora, historicamente, a categoria docente passou por um processo de empobrecimento e desvalorização, muito a partir de determinadas políticas públicas que imputavam, cada vez mais, maiores responsabilidades de sua atuação (RISTUM, 2010).

A "violência na escola" é que mais é propagada pela grande mídia e mais facilmente identificada por seus funcionários, gestores, professores e comunidade escolar. Largamente identificada em diversos estudos como "violência escolar", ela se manifesta como conflitos entre alunos, de aluno contra professor, da escola e do professor contra o aluno, entre seus funcionários. Além disso, há a violência do sistema sobre seus sujeitos, o que afeta, sobremaneira, as relações que acontecem na escola (RISTUM, 2010)..

Há, ainda, a "violência da escola". Esta refere-se diretamente à forma como as relações hierárquicas são constituídas dentro dos sistemas educacionais e que atingem diretamente as relações no interior da escola. Bourdieu (1989) denomina como "violência simbólica". Ela se configura pela exigência do cumprimento de prazos, das ações burocráticas que se sobrepõem ao trabalho pedagógico, de atendimento às demandas de alunos/as, de pais/mães, de submissão ao controle do Estado. Neste escopo, há ainda diversas desigualdade de gênero e das famosas "brincadeiras" que se fazem, principalmente, em relação às professoras da educação infantil e dos primeiros anos do ensino fundamental, apelidando-as de "professorinhas". Estes elementos funcionam como instrumentos estruturados e que estruturam o conhecimento e mantém uma lógica hierárquica de poder masculino (RISTUM, 2010). Para efeito desse artigo, este é o tipo de violência que mais permeou nossas análises.

Diante disso, verifica-se que docência é uma profissão feminina não apenas por conta de ter mais mulheres atuando, mas por ela ser uma profissão ligada a signos que são percebidos como característicos do gênero feminino. Não perceber a docência numa perspectiva de gênero é ocultar as desigualdades e violências simbólicas nas perspectivas generificadas existentes. A necessidade de formação de uma identidade docente é um exemplo de prática normativa e opressora presente na profissão ao tentar enquadrar um "jeito de ser professora", portanto, 
inscreve-se em enquadres de feminilidade ditos necessários para o exercício da docência..

"Ser mulher me faz, às vezes, infeliz": a violência de gênero na educação

A categoria mulher pode ser lida como um signo que performatizamos. Como já dito, não há uma essência feminina. Estes signos femininos são permeados por uma violência de gênero. Esta violência está presente tanto em mulheres dentro padrão 'bela, recatada e do lar' como para mulheres que não estão neste feminino hegemônico. Quando vivem violências, quando apanham de seus maridos ou amantes ou namorados, por exemplo, são culpabilizadas porque falam demais, porque não respeitam seus companheiros. De modo geral, as mulheres, em todas as formas de feminilidades, têm algo em comum: a banalização da violência contra si, elas não são a humanidade, elas são mulheres.

No Brasil, país mais transfóbico do mundo, uma mulher transexual ou travesti tem expectativa de vida de até trinta e cinco ${ }^{11}$ anos e essas mortes prematuras se dão principalmente pelo contexto do gênero não inteligível. As participantes da pesquisa narraram que suas vidas foram marcadas muito mais por uma violência simbólica do que propriamente uma violência física. Nesse sentido, o conceito de violência simbólica de Bourdieu (1989) nos ajuda a entender que as relações estão inscritas em uma dimensão de poder invisível ou simbólico. Os discursos são potentes produtores desse poder, bem como ações mais discretas e que estão "naturalizadas" como normais ou concordantes socialmente. Ele se constitui nas produções culturais de maneira que muitas vezes nem nos damos conta, como é natural falar 'formação de professores' é natural ouvir piadas dirigidas às professoras nas escolas ou diretores e diretoras reclamarem de suas roupas.

A professora Jasmine, mulher transexual, relata que vive, cotidianamente, uma violência velada, principalmente, por parte de seus pares: professores, professoras e funcionários. Sentiu-se violada ao assumir um cargo de chefia em sua escola: "Já passei por violência por parte de

11 Disponível em http://agenciabrasil.ebc.com.br/direitos-humanos/noticia/2015-11/com600-mortes-em-seis-anos-brasil-e-o-que-mais-mata-travestis-e Data do acesso 20/08/2016. Sigla que remeta a Lésbicas, gays, bissexuais e transexuais. Esta sigla origina-se do movimento social que busca direitos igualitários para pessoas que não estão na norma de inteligibilidade. 
funcionários e professores enquanto diretora transexual, como professora transexual. Mas, por parte dos alunos, nunca senti esta violência. Nunca me senti discriminada por eles." Ela continua destrinchando sua compreensão dessa violência que sofreu: "Muitas vezes, o que a sociedade entende como violência é apenas aquela que aparece, como uma agressão física, uma agressão verbal. Mas, na escola, ela acaba sendo muito velada. Há racismo, preconceito, discriminação e fica muito difícil perceber que há uma violência contra o outro."

Para Das (2011), os atos de violência contra as mulheres, a partir de suas pesquisas na Índia, levam-na a compreender as linguagens da dor que se inscrevem em uma violência coletiva sem precedentes. Segundo a autora, "as violações inscritas no corpo feminino (literal e figurativamente) e as formações discursivas em torno dessas violações, como vimos, tornaram visível a imaginação da nação como uma nação masculina." (DAS, 2011, p. 11).

O professor João coloca em questão algumas falas e atitudes que podem soar como brincadeira e que, no fundo, podem revelar uma violência contra o outro. As brincadeiras ocultam a violência e, muitas vezes, quem a sofre ainda sofre o constrangimento de ser vista como uma pessoa "chata", "sem senso de humor", "que não aceita 'brincadeiras"'. Ele relata que, ao chamar a atenção dos alunos sobre as formas como eles se tratam pode indicar uma ofensa em relação aos colegas. "Mas, tio, eu não estou falando nada demais. Estou brincando!", "Está falando, sim. E o que parece brincadeira, pode ser uma grande ofensa para o outro. Não é você quem tem que mensurar se o que você está dizendo ofende o outro. Quem decide se está sendo ofendido é o outro. Então, você não pode falar que o outro não está ofendido. O outro tem que ter espaço para não aceitar 'sua brincadeira' e você precisa refletir sobre isso."

A violência vivida na escola nem sempre é transparente. João conta um fato acerca da forma como outros professores também perpetuam imagens de violência simbólica. Ao relatar o fato de um professor de Educação Física obrigar as alunas a jogarem futebol, mesmo quando não desejam, há um indício de que, ao tentar construir uma suposta "igualdade de gênero", na verdade, ele impõe uma postura opressora. Ele não percebe como uma atitude opressora. João diz o seguinte: " o professor de educação física vira para mim e fala que na aula dele todo mundo joga futebol, querendo ou não querendo, pois não existe esse negócio de só menino é que joga futebol. Mas, ele não entende que a menina não 
quer jogar, como há meninos que também não querem jogar. Para mim, ele se acha avançado ao pensar que todos têm o direito de jogar futebol. Mas, será que o direito não seria o de não jogar porque não gosta ou não tem habilidade no esporte?"

Vianna e Farias (2011) argumentam que a figura do Estado é simbolicamente masculina. Os signos femininos, ao lutarem contra a violência do Estado, não apenas lutam por si, mas contra um Estado masculino que permite que mulheres percam seus filhos, sejam violadas. Um Estado que permite que mulheres morram de todas as maneiras. A partir deste testemunho da violência, pode-se perceber a falácia da harmonia e quanto esta custa às mulheres. Para as autoras, "o Estado é, antes de qualquer coisa, masculino, do mesmo modo que do outro lado estão as figuras eminentemente femininas: mães enterradas, mães que enterram." (VIANNA e FARIAS, 2011, p. 93)

As professoras, como funcionárias públicas, podem perceber um Estado que se omite das violências femininas que permeiam a docência. Desde baixa remuneração até situações de assédio moral vivenciadas nas relações com gestores/as por meio de exigências para atingir metas, para organizar a burocracia, atender à comunidade, para resolver problemas de indisciplina e mesmo de violência na escola.

A professora arla conta que, ao tentar entrar na sede da Secretaria de Educação do Munícipio onde trabalha, ela foi impedida por um funcionário e convidada a ter bom senso, pois não poderia entrar em trajes que ele considerava inadequados para o ambiente. A situação que levou esta professora e outras à Secretaria foi o fato de estarem com os salários atrasados e parcelados. O grupo dirigiu-se à Secretaria para reivindicar a regularização dos pagamentos. Diante disso, Carla respondeu o seguinte: "ele (o atendente da Secretaria) me disse que eu estava vestida inadequadamente para estar na Secretaria de Educação. Retruquei e ele me disse que eu precisava ter bom senso." A professora vestia uma roupa curta e justa (dentro dos padrões que o "Estado" define?).

Das (2011) discorda de um consenso que parece haver de que as mulheres para se constituírem em sujeitos precisam se sujeitarem a experiências, inclusive de violações cotidianas. A autora argumenta que mulheres ao narrarem suas violências vividas não apenas mostram como isso lhes causa danos, mas também como a concepção de harmonia não está tão estável assim. $O$ estar no mundo onde todas habitam de maneira harmoniosa é uma falácia. Os atos violentos, não apenas destroem o 
mundo que habitamos, mas também é importante entender como muIheres ritualizam este espaço. A vulnerabilidade feminina está marcada pelas normas de gênero que são potencializadas em situações de confronto. Mulheres podem ser violentadas apenas porque há uma certeza de que elas não vão revidar esta violência. As normas que colocam as mulheres numa maior vulnerabilidade são as mesmas que provocam uma violência inserida no sujeito generificado. Para Das (2011, p. 15)), "a formação do sujeito como sujeito com gênero é então moldada através de transações complexas entre violência como momento originário e a violência que se infiltra nas relações correntes e se torna uma espécie de atmosfera que não pode ser expelida para fora."

Há violências de gênero que apenas mulheres presenciam. A professora Cristiane diz que desejava ser homem apenas para não sofrer cobranças e exigências que sofre somente pelo fato de "ser mulher." Segundo ela, "ser mulher me faz infeliz, de vez em quando. Eu queria ter um poderzinho masculino. A gente tem que responder a muita coisa, justificar nossos desejos, nossas ações, justificar nossos pensamentos. Já ouvi diversas vezes que eu pareço um homem por ser prática, pouco sensível, ríspida. Isso me irrita profundamente. Eu quero sentar do jeito que eu quiser, quero fazer do jeito que eu quiser, quero ser e desejar do que jeito que eu quiser. Se eu fosse homem, não precisava dar satisfações sobre quem eu sou".

Ela ainda destaca uma situação de violência que vivenciou em uma escola. É uma professora lésbica e, por tal orientação, foi rejeitada por quase $80 \%$ de uma turma. Disse que não teve apoio do diretor que, imediatamente, a dispensou do trabalho, alegando que ela era 'inexperiente para a sala de aula": "Tive uma rejeição de quase $80 \%$ de uma turma porque não gostavam do como eu manejava a turma. Tive que ouvir do Diretor que era principiante e que as portas da escola estavam abertas, mas que deveria, antes, adquirir mais experiência. Nunca voltei. Depois foi que percebi que sofri lesbofobia."

Das (2011) coloca que nossa maneira de estar com outros tem sido brutalmente danificada por estas violências. Para ela, o ato de testemunhar, compreendendo que os não-ditos são processos de linguagem, produz conhecimento. Ela denomina de "conhecimento venenoso" . A dor, o sofrimento, as violências brutais servem como produtores desse conhecimento. Isso implica pensar fora do óbvio semântico. As violências não são apenas eventos de destruição, mas também se constituem em processo na construção de sujeitos e linguagens da dor e do sofrimento. 
Das (2011) não está apenas preocupada em discutir uma intercessão entre gênero feminino e violência, mas sim, em entender como o gênero feminino está imbricado na formação desse conhecimento venenoso. Como as mulheres performatizam seu gênero diante das violências? O cotidiano da escola, em que corpos de mulheres professoras habitam, é também um espaço de múltiplas violências. Das (2011) questiona o que as violências, a dor e o sofrimento têm provocado na subjetividade das mulheres. Afirma que é necessário

\begin{abstract}
perguntar não só como a violência étnica ou comunal foi perpetrada por atos de violação específicos de gênero, como o estupro, mas também como as mulheres tomaram esses signos nocivos de violação e os re-ocuparam através do trabalho de domesticação, ritualização e re-narração. (DAS, 2011, p.11)
\end{abstract}

Cristiane relata que após declarar sua homossexualidade, não manteve um relacionamento mais profundo com sua família, especificamente com sua mãe, o que lhe desencadeou uma síndrome do pânico. O sofrimento é perceptível: " há momentos que não dá pra resistir. Os ataques são muitos e você tem que estar bem equilibrada para não cair no discurso alheio. Eu tenho outro discurso, outro modo de vida, outro modo de pensar. Às vezes, eu fraquejo, mas não caio."

O silêncio diante de uma violência é uma das normas que são naturalmente aceitas para o feminino. A professora Letícia, também lésbica, relatara que teve receio de contar para suas famílias a respeito de sua sexualidade. Letícia aponta que tinha medo de envergonhar a sua avó, pois temia que ela não compreendesse. Ela, atualmente, sabe da orientação sexual da neta e fora a pessoa de sua família que mais a acolheu: "Antes, eu me preservava muito por causa da minha família. A gente pensa muito no padrão que a família segue, ou imaginou que você seguiria, e tenho muito medo de magoar as pessoas que amo. Mas, quanto à aceitação, nunca tive problema com isso. Me entendi como gay e sempre me aceitei de boa. Agora, não queria magoar a minha avó, que é de outra época, outro momento, os ensinamentos dela foram outros. Não queria impor, fazer ela aceitar a minha condição. Não queria que ela vivesse isso. Por causa da idade e tudo mais, então eu preferi não abri antes. Agora, está tudo bem. Ela está entendendo melhor."

Este conceito de conhecimento venenoso pode trazer contribuições interessantes para as relações pedagógicas mais emancipatórias. 
Ao pensarmos nesta opressão presente na escola, precisamos entender como as violências evidenciadas estão relacionadas ao que as docentes vivenciam.

As normas de gênero postas às mulheres docentes influenciam em suas relações em sala de aula. Um espaço mais democrático em sala de aula, talvez, passe pela desconstrução das normas de gênero que a docência reitera. A professora Jasmine considera que precisamos refletir sobre como é nossa educação para pensarmos em outras formas de educar: "Na verdade, acho que a gente sempre reproduz a opressão que nós sofremos, seja pela família, seja pela escola. Muitos professores parecem ensinar do jeito que aprenderam. Impõem as mesmas repressões, os mesmos castigos. Se não pararmos para refletir sobre as situações de violência, se transforma num círculo vicioso."

Mulheres ao darem testemunho sobre a violência reabitam o espaço de outra maneira. O testemunho mostra que estes espaços sociais que antes poderiam aparentar serem harmoniosos, são na verdade marcados pela destruição. A mulher professora mostra que a escola está longe de ser um ambiente democrático, harmônico e de igualdade de gênero. A violência narrada por professoras revela que os danos não são causados apenas a elas, mas também a um todo: não é possível pensar essa violência sem entender como ela contamina a escola. Testemunhar esta violência significa mostrar como há uma morte das relações. A violência institucional deve ser encarada, percebida, desnaturalizada para ser combatida. Das (2011) afirma que:

Isso é o que quero dizer pela importância de descobrir meios de falar sobre a experiência de testemunhar: que se nossa maneira de estar-com-os-outros tiver sido brutalmente estragada, então o passado entra no presente, não necessariamente como memória traumática, mas como conhecimento venenoso. Esse conhecimento pode ser enfrentado apenas pelo conhecimento através do sofrimento. (DAS, 2011, p. 35)

As narrativas sobre as violências, a dor e o sofrimento podem se transformar em mecanismos de constituir redes de resistência e, portanto, possibilidades de construir lutas emancipatórias na perspectiva das relações de gênero no campo das feminilidades docentes, entendendo que falar em feminilidades, e não em feminilidade, é perspectivar 
a diversidade que habita o espaço social e a escola. Ao testemunhar as opressões vivenciadas, professoras podem ressignificar suas próprias vozes, seus próprios pensamentos, suas próprias práticas e suas próprias feminilidades.

\section{Redes de resistência e possibilidades emancipatórias}

Pensar a docência a partir de outras configurações da categoria "mulher" pode potencializar as formas de resistir aos preconceitos, às discriminações, às violência que envolvem as relações no interior das escolas. Na escola, ainda há resistências em discutir as questões de gênero, bem como de romper com a visão conservadora de que há um ideal de professora, um ideal de mulher professora a ser seguido. Por outro lado, as resistências à homogeneização, à unicidade do conceito de mulher permitem ampliar as lutas por emancipação das normas e das violências promovidas, principalmente, pelo Estado.

Há saberes que suportamos conhecer e outros que nos angustiam. O professor João, que incorpora uma drag queen, nos dá esta dimensão da pluralidade do ser mulher e questiona o fato de temas considerados polêmicos serem assumidos pela escola como fonte de novos conhecimentos a serem construídos. Para ele, "a escola é um campo de relações complexas e conflitantes. O tempo todo,estamos mediando as relações e a escola, muitas vezes, se omite de discutir determinados temas porque considera polêmicos. Trazer o debate sobre o que acontece na vida real, como as condições de violência a que mulheres, gays, travestis e transexuais estão submetidos é fundamental para pensarmos numa sociedade diferente".

Podemos dizer que, ainda que o caráter de feminilidade ainda seja padrão na docência, há outras feminilidades habitando o espaço escolar e desencadeando novas formas de pensar o ser professora. Desde o processo de redemocratização do país, outros sujeitos vêm ocupando a escola: são alunos/as e a professores/as mulheres, mulheres travestis, mulheres negras, mulheres transexuais, mulheres lésbicas, mulheres drag queens... Estas outras feminilidades não estão ocupando a escola de forma tranquila. Ocupam diante de muitas resistências e, ao mesmo tempo, elas resistem também. A presença dessas mulheres, dessas outras feminilidades arejam o lugar do conhecimento com outras possibilidades de pensar, existir, resistir e re-existir. 
Ao se considerar uma "mulher puta"12, a professora Carla exerce uma outra forma de docência que se coloca como mais livre, menos engessada, menos padrão, menos submissa. Tal situação é rica, porque leva-nos a perceber que sua sexualidade não interfere no exercício da docência. Isso poderia ser visto como óbvio, no entanto, quando nos lembramos que há exigências institucionais ou mesmo da conduta padrão de que as professoras mantenham um certo ar recatado sexual, vemos o quanto é preciso desconstruir o paradigma da professora "recatada e do lar". Carla diz: "Eu sou quem eu sou. Eu sou uma "puta" professora. Faltou oportunidade para eu cair na vida, então eu caí no magistério. Não acho que o fato de me vestir assim ou assado, faça de mim uma boa ou má professora. Meus alunos me adoram. Dizem que me visto muito bem e muito colorido. Não me encaixo em padrão de professorinha".

Os relatos sobre as diversas feminilidades no magistério contribuem para superarmos as normas cisgênera e heteronormativa. Visibilizar estas feminilidades desconstrói este padrão de feminino hegemônico. João afirma que não é possível medir quem é mais "pintosa"13, no sentido de não que não podemos julgar a sexualidade de uma pessoa, não podemos mais aceitar que performatividades de gênero e sexualidades sejam patologizadas se não estão no padrão cisgênero e heterossexual: "Assim como eu não determino o tamanho da saia de uma mulher e determino quem é santa ou é profana, eu também não posso determinar quem é mais 'pintosa' ou não por causa do tamanho da franja ou dos trejeitos. Eu sou contra qualquer tipo de padrão. Procuro me posicionar de forma bem contundente sobre isso."

O professor João performatiza a Drag Queen chamada Laura. Para ela, performatizar Laura foi importante para Ihe trazer oportunidades para discutir gênero na escola. É interessante, pois, uma Drag Queen na escola, por si só, já é uma subversão. Ao tratar das normas de gênero, parece haver tais espaços de emancipação e de subversão. João afirma a necessidade de a escola tratar, de forma sistemática, as questões de gênero. "A gente ainda não conseguiu entender o direito que cada cidadão tem sobre seu corpo, sua identidade. Então, a Laura contribuiu muito na minha carreira docente e me permitiu hoje discutir muito mais os papeis

12 A expressão "puta" utilizada por Carla refere-se a uma sexualidade mais livre e não como "profissional do sexo".

13 A expressão "pintosa" se refere a homossexuais masculinos que performatizam signos ditos mais femininos.

Revista Educação e Emancipação, São Luís, v. 10, n. 4, ed. especial, set./dez.2017 
de gênero, as desigualdades, as violências. Ao retratar as violências sofridas, eu percebo o quanto a escola ainda é um lugar segregador e a lutar mais ainda para que deixe de ser este lugar de segregação."

\section{Referências}

AGAMBEN, Giorgio. Estado de exceção. São Paulo: Boitempo, 2004.

BOURDIEU, Pierre. A Dominação Masculina. Rio de Janeiro, Bertrand Brasil,1989.

BRASIL. Relatório nacional TALIS: pesquisa internacional sobre ensino e aprendizagem. MEC/INEP: Brasília, 2014.

BUTLER, Judith. Quadros de guerra-Quando a vida é passível de luto? Rio de Janeiro: Editora Civilização Brasileira.2015.

CONNELL, Raewyn. PEARSE, Rebecca. Gênero: uma perspectiva global. São Paulo: InVeros, 2015.

COUTINHO, Maria Lúcia Rocha. A narrativa oral, a análise de discurso e os estudos degênero.Estud.Psicol.,Natal,v.11,n.1,jan./abr.2006.Disponível em: <http://www.scielo.br/scielo.php?script=sci_arttext\&pid=413-294X $2006000100008>$. Acesso em: 30 ago.2017.

DAS, Veena. $\mathrm{O}$ ato de testemunhar: violência, gênero e subjetividade. Cadernos Pagu, Campinas, n. 37, p. 9-41, jul./dez. 2011.

FAUSTO-STERLING, Anne.Dualismoem duelo.Cadernos Pagu, Campinas: Núcleo de Estudos de Gênero - Pagu, n. 17/18, p. 9-79, 2001.

HARDING, Sandra. A instabilidade das categorias analíticas na teoria feminista. Estudos feministas, v. 1, n. 1, p. 7-32, 1993.

NICHOLSON, Linda. Interpretando o gênero. Estudo feministas, Florianópolis, v. 8, n. 2, p. 09-41, 2000. Disponível em: < http://www. marcoaureliosc.com.br/nicholson.pdf >. Acesso em: 30 ago. 2017.

RISTUM, Milena. Violência na escola, da escola e contra a escola. In: ASSIS, S.G.; CONSTANTINO, P., and AVANCl, J.Q. (Orgs.). Impactos da violência na escola: um diálogo com professores [online]. Rio de Janeiro: Ministério da Educação Editora FIOCRUZ, 2010. Disponível em:< http://books.scielo.org/id/szv5t/pdf/assis-9788575413302-05.pdf>. Acesso em: 30 ago. 2017. 
SCOTT, Joan. Gênero: uma Categoria Útil de Análise Histórica. Educação e Realidade, Porto Alegre, v. 20, n. 2, p. 71-99, jul./dez.1995. Disponível em: < https://archive.org/details/scott_gender >. Acesso em: 30 ago. 2017.

SILVA, Vera Lúcia Gastar da. Profissão: professora! In: CAMPOS, Maria Christina Siqueira de Souza, SILVA, Vera Lúcia Gaspar da (org) Feminização do magistério: vestígios do passado que marcam o presente. Bragança Paulista: EDUSF, 2002. p. 95-122.

VIANNA, Adriana. FARIAS, Juliana. A guerra das mães: dor e política em situações de violência institucional. Cadernos Pagu, n. 37, p. 79-116, jul./dez, 2011.

WAISELFISZ, Julio Jacob. Mapa da violência 2015: homicídio de mulheres no Brasil, Flacso/Brasil: Brasília, 2015. Disponível em: <http:// www.mapadaviolencia.org.br/pdf2015/MapaViolencia_2015_mulheres. pdf. >. Acesso em: 30 ago.2017.

Recebido em: Setembro 2017

Aprovado em: Novembro 2017 